\title{
Formation of Category Representations in Superior Temporal Sulcus
}

\author{
Marieke van der Linden ${ }^{1}$, Miranda van Turennout ${ }^{1}$, \\ and Peter Indefrey ${ }^{1,2,3}$
}

\begin{abstract}
The human brain contains cortical areas specialized in representing object categories. Visual experience is known to change the responses in these category-selective areas of the brain. However, little is known about how category training specifically affects cortical category selectivity. Here, we investigated the experience-dependent formation of object categories using an fMRI adaptation paradigm. Outside the scanner, subjects were trained to categorize artificial bird types into arbitrary categories (jungle birds and desert birds). After training, neuronal populations in the occipito-temporal cortex, such as the fusiform and the lateral occipital gyrus, were highly sensitive to perceptual
\end{abstract}

\section{INTRODUCTION}

Learning to categorize the world starts at a very young age. Infants of only 4 months of age can form categorical representations (Mareschal \& Quinn, 2001). This process continues throughout adulthood, with learning and experience shaping the borders of existing categories and forming entirely new categories. Brain imaging studies investigating the formation and alteration of cortical object category representations in the adult human brain have linked increased perceptual expertise to neuronal changes in the occipito-temporal cortex. When subjects gain experience with discriminating a novel object category, increases in activity have been found in the right middle fusiform gyrus (Weisberg, van Turennout, \& Martin, 2007; Gauthier, Tarr, Anderson, Skudlarski, \& Gore, 1999), the lateral occipital gyrus (Op de Beeck, Baker, DiCarlo, \& Kanwisher, 2006), and the middle occipital gyrus (Moore, Cohen, \& Ranganath, 2006). Activity in the occipito-temporal cortex has also been found to be selectively enhanced for objects from a category with which subjects have extensive experience, such as birds and cars (Xu, 2005; Gauthier, Skudlarski, Gore, \& Anderson, 2000) or lepidoptera (Rhodes, Byatt, Michie, \& Puce, 2004). These findings indicate that experience with an ob-

\footnotetext{
${ }^{1}$ Radboud University Nijmegen, The Netherlands, ${ }^{2}$ Max Planck Institute for Psycholinguistics, Nijmegen, The Netherlands, ${ }^{3}$ Heinrich Heine University, Düsseldorf, Germany
}

stimulus differences. This sensitivity was not present for novel birds, indicating experience-related changes in neuronal representations. Neurons in STS showed category selectivity. A release from adaptation in STS was only observed when two birds in a pair crossed the category boundary. This dissociation could not be explained by perceptual similarities because the physical difference between birds from the same side of the category boundary and between birds from opposite sides of the category boundary was equal. Together, the occipito-temporal cortex and the STS have the properties suitable for a system that can both generalize across stimuli and discriminate between them.

ject category modulates the underlying neuronal representation. However, it is not clear whether these experiencedependent changes could be explained by visual experience alone or whether they reflect the formation of object categories. Previously, we found that learning to categorize highly similar bird types led to a selective increase in activity in the right middle fusiform gyrus (van der Linden, Murre, \& van Turennout, 2008). Critically, this increase was not present for bird types to which the subjects were exposed to the same amount but for which a category's distinguishing features could not be learned because of random feedback. We attributed this selectivity to increased responsiveness of neurons in the right middle fusiform gyrus to those object features that facilitate categorization.

Taken together, increased perceptual expertise is linked to neuronal changes in the occipito-temporal cortex. However, in all these studies, category membership was perception based; that is, perceptually similar objects belonged to the same category. Recently, Jiang et al. (2007) used fMRI to investigate how cortical representations in the adult human brain are shaped when perceptually dissimilar objects are grouped in the same category. In their fMRI study, a discrete boundary between similar-looking nonnatural objects (cars) belonging to different categories was established by training. Car stimuli were morphed with each other, allowing comparison of cars on the same side of the category boundary (belonging to the same car type) with cars with a similar physical difference but on opposite sides of the category boundary (belonging to different car types 
and belonging to either the same category or a different category). They found sharpening of the representation after categorization training in the lateral occipital gyrus. However, the response in this region was perception based and not selective for category membership. The pFC did show category selectivity that was not perception based; however, this selectivity was task dependent and only obtained when the subjects performed a categorization task.

In the present study, we used an fMRI adaptation paradigm (Grill-Spector, Henson, \& Martin, 2006), similar to Jiang et al. (2007), to investigate experience-dependent formation of cortical category representations. Grill-Spector and Malach (2001) have shown that fMRI adaptation can be used to probe the sensitivity of neuronal populations. The nature of neural stimulus representations can be revealed when hemodynamic responses are selectively affected by repeating or changing particular stimulus attributes. This makes the adaptation technique a useful tool to make inferences about neural sensitivity in specific cortical regions (Cohen Kadosh, Cohen Kadosh, Kaas, Henik, \& Goebel, 2007; Pourtois, Schwartz, Seghier, Lazeyras, \& Vuilleumier, 2005; Grill-Spector et al., 1999).

Previous studies have demonstrated that regions involved in representing stimuli from a certain class adapt selectively to repeated presentation of objects from this class. For example, the fusiform face area shows sensitivity to repeated presentation of faces (Andrews \& Ewbank, 2004), and the parahippocampal place area shows sensitivity to the repetition of places (Ewbank, Schluppeck, \& Andrews, 2005; Epstein, Graham, \& Downing, 2003). In addition, fMRI adaptation paradigms have been successfully applied to identify cortical areas sensitive to identity change (Gilaie-Dotan \& Malach, 2007; Jiang et al., 2006; Loffler, Yourganov, Wilkinson, \& Wilson, 2005; Rotshtein, Henson, Treves, Driver, \& Dolan, 2005) and category change (Jiang et al., 2007). Regarding the category of animals, the lateral fusiform gyrus and the STS showed reduced activity only for repeated animals and not for repeated tools (Chao, Weisberg, \& Martin, 2002). Additional tasks, such as animal picture processing, reading animal names, and answering questions about animals, produced category-related activity in the same regions (Chao, Haxby, \& Martin, 1999). Because not only pictures of the animals but also words and questions elicited category-related activations in STS, the activity in the temporal cortex seems to reflect stored information about animals rather than the physical features of the animals, which are believed to be stored in the fusiform gyrus.

We trained subjects to successfully categorize four bird types that were highly similar into two arbitrary bird categories (desert birds and jungle birds). During scanning, the subjects did not categorize the bird types. We were interested in finding training-induced category representations that were activated in the absence of a categorization task and that were independent of the shape of the birds. We hypothesized to find experience-dependent selectivity to the birds in the occipito-temporal cortex and STS.

\section{METHODS}

\section{Subjects}

Twenty-eight healthy right-handed participants (24 women, mean age $=21.9$ years, range $=18-35$ years) with no neurological history participated in the experiment. Two subjects were excluded because of excessive motion (i.e., more than $3 \mathrm{~mm}$ ). After training, 18 subjects (15 women, mean age $=22.5$ years, range $=18-35$ years) were able to categorize at least three bird types. These subjects were included in a within-subject analysis. All subjects had normal or corrected-to-normal vision. Subjects were paid for their participation. All subjects gave written informed consent.

\section{Stimuli}

The stimuli consisted of pictures of computer-generated birds that were constructed in a three-dimensional model manipulation program (Poser 4 by Curious Labs, Santa Cruz, CA). First, six prototype birds were constructed from a base bird (Songbird Remix by Daz3d, Draper, UT; see Figure 1a). Parts of the bird that were manipulated included its trunk, tail, beak, head shape, cheeks, brow, and eye position. Next, to create different exemplars for each category, each of the six prototype birds was morphed with all other birds at ratios of 95:5, 90:10, 80:20, 75:25, 70:30, 65:35, 60:40, and 55:45 (Figure 1b). The category boundary

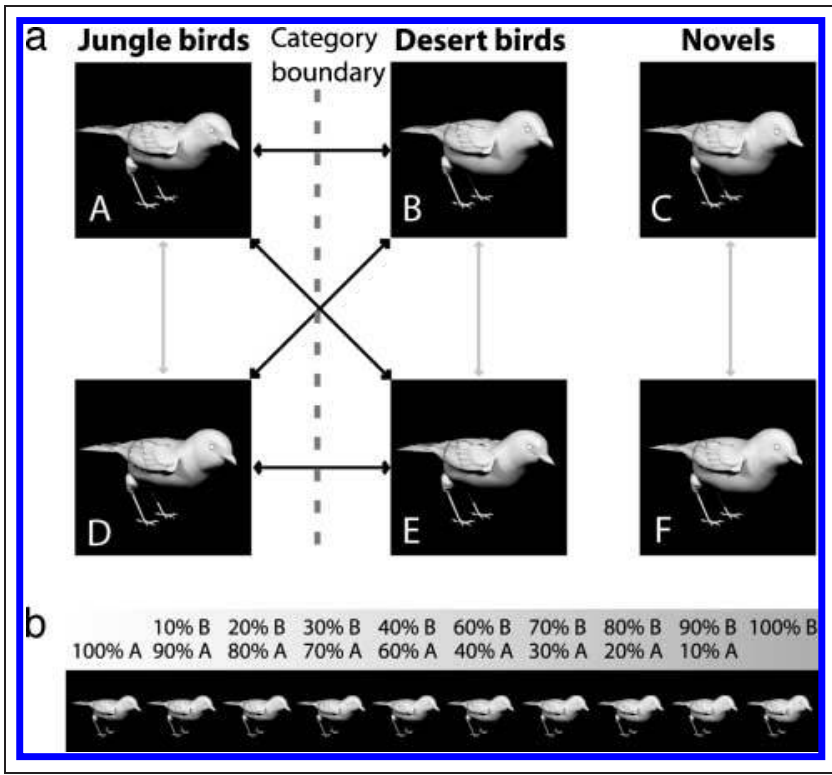

Figure 1. Creation of the stimulus set. (a) Each of the six prototype birds (i.e., A-F) was morphed with all other birds to create exemplars for each of the different bird types. Four bird types were grouped into two arbitrary bird categories, desert birds (e.g., A and D) and jungle birds (e.g., B and E). Two bird types (e.g., C and F) were not used during training and acted as novel controls during scanning. The assignment of birds into categories was counterbalanced over subjects. (b) By systematically morphing each of the six prototype birds with all other birds, the different exemplars for each bird type were created. Shown is an example of morphing bird type A and bird type B at morph ratios of 90:10, 80:20, 70:30, and 60:40. 
Figure 2. (A) Training design. During the training sessions, participants were presented with a series of bird exemplars.

They performed a categorization task in which they labeled each exemplar as either a "desert bird" or a "jungle bird" by pressing a button. Category learning was established by providing corrective feedback after each trial. (B) fMRI adaptation design. The experimental design included four adaptation pair types: $\mathrm{S}_{\mathrm{e}} \mathrm{S}_{\mathrm{t}} \mathrm{S}_{\mathrm{c}}$ (birds in a pair are the exact same bird exemplar, the same bird type, and the same category), $\mathrm{D}_{\mathrm{e}} \mathrm{S}_{\mathrm{t}} \mathrm{S}_{\mathrm{c}}$ (birds in a pair are different bird exemplars but the same bird type and the same category), $\mathrm{D}_{\mathrm{e}} \mathrm{D}_{\mathrm{t}} \mathrm{S}_{\mathrm{c}}$ (the birds in pair are different bird exemplars and different bird types but from the same category), and $\mathrm{D}_{\mathrm{e}} \mathrm{D}_{\mathrm{t}} \mathrm{D}_{\mathrm{c}}$ (birds in a pair are different bird exemplars, different bird types, and different categories). The morph distance between birds within a pair was always $0 \%$ for $\mathrm{S}_{\mathrm{e}} \mathrm{S}_{\mathrm{t}} \mathrm{S}_{\mathrm{c}}$ repetitions and $20 \%$ or $30 \%$ for all other conditions. (C) fMRI adaptation trial timing. A trial started with an asterisk (fixation) for 400 msec after which the first bird picture (picture1) was shown for $500 \mathrm{msec}$, followed by a blank screen interval (blank) of $400 \mathrm{msec}$ and the second bird picture (picture2) of a bird for $500 \mathrm{msec}$. After the onset of the second picture, the subject could respond. They pressed a button indicating whether they recognized the second bird from the training sessions ("old" or "new" bird). The interstimulus interval was jittered between 3600 and 4400 msec in steps of 200 msec. was set at $50 \%$. As a result, stimuli that were close to but on opposite sides of the category boundary were visually similar but belonged to different categories. Morphing happened smoothly between corresponding points on the birds. Each bird was colorless, rendered under the same lighting and camera settings, and exported as an image. Images had identical shading and scale. The images measured $300 \times 300$ pixels in the training sessions and were slightly reduced in size $(250 \times 250$ pixels $)$ in the scanning sessions. In addition, a set of scrambled bird pictures was constructed to function as a low-level visual baseline in the scan session.

\section{Procedure}

Four bird types were arbitrarily assigned to two categories (jungle birds and desert birds; see Figure 1a). The two bird types constituting a category were counterbalanced across subjects. In addition, two bird types were not trained and acted as novel controls in the scan session.

\section{Training}

Subjects were instructed to categorize four bird types in two bird categories (desert and jungle birds). During train- ing, the subjects performed a categorization task on pictures of different exemplars of the bird types (see Figure 2A). They indicated for each bird picture whether it was a jungle bird or a desert bird with a button press of the index or the middle finger of the right hand. After each response, they received feedback whether their response was correct, false, or too late. The assignment of bird category to finger was switched every block of training to avoid mapping of a bird category to a finger. Each bird picture was shown for $1 \mathrm{sec}$, after which the subject had $2 \mathrm{sec}$ to give a response. Feedback was presented for $250 \mathrm{msec}$ and was followed by a blank screen of $250 \mathrm{msec}$, after which the next trial commenced. Each block of training lasted $10 \mathrm{~min}$ and contained 160 exemplars (40 per bird type). Each exemplar was shown once during a block. Each training session contained eight blocks. Training sessions took place on consecutive days. Subjects were scanned after completing three training sessions.

\section{fMRI Scanning Session}

An adaptation paradigm was used during scanning. The adaptation condition was determined by the relation between the two birds that were rapidly presented in a pair. Four types of adaptation conditions were used 
(Figure 2B). In the first condition, birds in a pair consisted of the exact same exemplar from the same bird type and the same category $\left(\mathrm{S}_{\mathrm{e}} \mathrm{S}_{\mathrm{t}} \mathrm{S}_{\mathrm{c}}\right)$, for example, jungle bird type A 60\% and jungle bird type A 60\%. In the second condition, birds in a pair were different exemplars of the same bird type and the same category $\left(D_{e} S_{t} S_{c}\right)$, for example, jungle bird type A 60\% and jungle bird type A $80 \%$. In the third condition, the birds in a pair were different exemplars of different bird types but of the same category $\left(D_{e} D_{t} S_{c}\right)$, for example, jungle bird type A 60\% and jungle bird type B 60\%. In the fourth condition, birds were different exemplars of different bird types and belonged to different categories $\left(\mathrm{D}_{\mathrm{e}} \mathrm{D}_{\mathrm{t}} \mathrm{D}_{\mathrm{c}}\right)$, for example, jungle bird type A 60\% and desert bird type C 60\%. Importantly, the physical distance between birds from the same $\left(D_{e} S_{t} S_{c}\right.$ and $\left.D_{e} D_{t} S_{c}\right)$ and opposite sides $\left(D_{e} D_{t} D_{c}\right)$ of the category boundary was kept equal. This physical difference was 20\% for half of the trials and 30\% for the other half. For each adaptation condition, there were 20 trials per morph level distance. In addition, there were 40 pairs of scrambled images that functioned as a baseline.

For the novel birds, the adaptation conditions were $\mathrm{S}_{\mathrm{e}} \mathrm{S}_{\mathrm{t}} \mathrm{S}_{\mathrm{c}}, \mathrm{D}_{\mathrm{e}} \mathrm{S}_{\mathrm{t}} \mathrm{S}_{\mathrm{c}}$, and $\mathrm{D}_{\mathrm{e}} \mathrm{D}_{\mathrm{t}} \mathrm{D}_{\mathrm{c}}$. Novel birds were not trained. As such, novel bird types could not be grouped into the same category. Therefore, there was no $\mathrm{D}_{\mathrm{e}} \mathrm{D}_{\mathrm{t}} \mathrm{S}_{\mathrm{c}}$ condition for novel birds. During scanning, the subjects performed an old/new task. They indicated for each second bird in the pair, whether they remembered it from the training session or not. Subjects responded with the index ("yes") and the middle finger ("no") of the right hand on an MR-compatible response box (Lumitouch by Photon Control, Burnaby, Canada). To balance the number of "yes" and "no" responses, we included $\mathrm{D}_{\mathrm{e}} \mathrm{D}_{\mathrm{t}} \mathrm{D}_{\mathrm{c}}$ filler pairs of which the first bird was trained and the second bird was novel.

A trial started with an asterisk for 400 msec after which a bird picture was shown for $500 \mathrm{msec}$, followed by a blank screen interval of $400 \mathrm{msec}$ and another picture of a bird for $500 \mathrm{msec}$. After the onset of the second picture, the subject could respond. The interstimulus interval was jittered between 3600 and $4400 \mathrm{msec}$ in steps of $200 \mathrm{msec}$ (see Figure 2C). The order of trials was pseudorandom to have an optimal distance between two pairs of the same condition and morph level difference.

\section{fMRI Scanning Parameters}

For each subject, 939 whole brain echo-planar imaging images (35 slices, $3 \mathrm{~mm}$ thick, no gap, repetition time $=$ $2250 \mathrm{msec}$, echo time $=30$, flip angle $=70^{\circ}$, field of view $=$ $19.2 \mathrm{~cm}$, matrix $=64 \times 64$ ) were acquired on a 3-T wholebody MR scanner (Magnetom TRIO by Siemens Medical Systems, Erlangen, Germany). In addition, a high-resolution structural T1-weighted three-dimensional magnetization prepared rapid acquisition gradient-echo sequence im- age was obtained after the functional scan (192 slices, voxel size $=1 \times 1 \times 1 \mathrm{~mm}$ ).

\section{fMRI Analysis}

Data analysis was done using BrainVoyager QX (by Brain Innovation, Maastricht, The Netherlands). The first two volumes were discarded to allow for T1 signal equilibrium. The following preprocessing steps were performed: slice scan time correction (using sinc interpolation), linear trend removal, temporal high-pass filtering to remove low-frequency nonlinear drifts of 3 or fewer cycles per time course, and three-dimensional motion correction to detect and to correct for small head movements by spatial alignment of all volumes to the first volume by rigid body transformations. Estimated translation and rotation parameters were inspected and never exceeded $3 \mathrm{~mm}$. Coregistration of functional and three-dimensional structural measurements was computed by relating $\mathrm{T} 2 *$-weighted images and the T1-weighted magnetization prepared rapid acquisition gradient-echo measurement, which yields a four-dimensional functional data set. Structural threedimensional and functional four-dimensional data sets were transformed into Talairach space (Talairach \& Tournoux, 1988) and spatially smoothed with a Gaussian kernel $(\mathrm{FWHM}=6 \mathrm{~mm})$. The expected BOLD signal change was modeled using a gamma function $(\tau=2.5 \mathrm{sec}, \delta=1.5)$ and convolved with the second event (Boynton, Engel, Glover, \& Heeger, 1996). Statistical analyses were performed in the context of the general linear model. Both fixed and random-effects group analyses were performed. The statistical threshold was set at $p<.05$, false discovery rate (FDR)-corrected and with a cluster threshold of $50 \mathrm{~mm}^{3}$.

We defined areas that showed adaptation for bird pairs consisting of the exact same exemplar of the same bird type and the same category $\left(\mathrm{S}_{\mathrm{e}} \mathrm{S}_{\mathrm{t}} \mathrm{S}_{\mathrm{c}}\right)$ relative to bird pairs consisting of birds from different categories $\left(\mathrm{D}_{\mathrm{e}} \mathrm{D}_{\mathrm{t}} \mathrm{D}_{\mathrm{c}}\right)$ using the contrast $\mathrm{S}_{\mathrm{e}} \mathrm{S}_{\mathrm{t}} \mathrm{S}_{\mathrm{c}}<\mathrm{D}_{\mathrm{e}} \mathrm{D}_{\mathrm{t}} \mathrm{D}_{\mathrm{c}}$. We did this for novel, trained, and both novel and trained birds. Next, clusters showing a significant adaptation effect were selected for a more sensitive ROI analysis. The ROI time courses were standardized, so that beta weights (regression coefficients) of predictors, as indices of effect size, reflect the BOLD response amplitude of one condition relative to the variability of the signal. Beta weights were obtained for all voxels within these ROIs, per subject and per adaptation condition $\left(\mathrm{S}_{\mathrm{e}} \mathrm{S}_{\mathrm{t}} \mathrm{S}_{\mathrm{c}}, \mathrm{D}_{\mathrm{e}} \mathrm{S}_{\mathrm{t}} \mathrm{S}_{\mathrm{c}}, \mathrm{D}_{\mathrm{e}} \mathrm{D}_{\mathrm{t}} \mathrm{S}_{\mathrm{c}}\right.$, and $\mathrm{D}_{\mathrm{e}} \mathrm{D}_{\mathrm{t}} \mathrm{D}_{\mathrm{c}}$ for trained and $\mathrm{S}_{\mathrm{e}} \mathrm{S}_{\mathrm{t}} \mathrm{S}_{\mathrm{c}}, \mathrm{D}_{\mathrm{e}} \mathrm{S}_{\mathrm{t}} \mathrm{S}_{\mathrm{c}}$, and $\mathrm{D}_{\mathrm{e}} \mathrm{D}_{\mathrm{t}} \mathrm{D}_{\mathrm{c}}$ for novel bird types). Random effects analyses were performed on the subject-averaged beta weights by applying paired $t$ tests, with a threshold set at $p<.05$. All $t$ tests were two-tailed.

To test for category selectivity, we performed a conjunction analysis of three contrasts for fixed effects with a standard "minimal $t$ statistic" approach (Nichols, Brett, Andersson, Wager, \& Poline, 2005), which is equivalent 
to a logical AND of the contrasts at the voxel level. To obtain a statistical threshold for the conjunction analysis, we estimated the probability of finding a voxel that is significant in each and all three contrasts (i.e., the joint probability). We conjoined all contrasts where there is a difference in category membership $\left(\mathrm{S}_{\mathrm{e}} \mathrm{S}_{\mathrm{t}} \mathrm{S}_{\mathrm{c}}<\mathrm{D}_{\mathrm{e}} \mathrm{D}_{\mathrm{t}} \mathrm{D}_{\mathrm{c}}\right) \cap$ $\left(\mathrm{D}_{\mathrm{e}} \mathrm{S}_{\mathrm{t}} \mathrm{S}_{\mathrm{c}}<\mathrm{D}_{\mathrm{e}} \mathrm{D}_{\mathrm{t}} \mathrm{D}_{\mathrm{c}}\right) \cap\left(\mathrm{D}_{\mathrm{e}} \mathrm{D}_{\mathrm{t}} \mathrm{S}_{\mathrm{C}}<\mathrm{D}_{\mathrm{e}} \mathrm{D}_{\mathrm{t}} \mathrm{D}_{\mathrm{C}}\right)$. The least significant contrast determines the $p$ value of the conjunction, that is, $p<.05$, FDR-corrected.

\section{Behavioral Data Analysis}

For the training data, response times for the correct trials and the percentage of correct trials were computed for each subject. These dependent variables were collapsed over bird categories and submitted to a Training Session $\times$ Morph Level ANOVA with repeated measures. Training session consisted of three levels (first, second, and third training session), and morph level consisted of eight levels (55\%, 60\%, 65\%, 70\%, 75\%, 80\%, 90\%, and 95\%). All significant interactions were explored with additional ANOVAs for each training session. Greenhouse-Geisser corrections were applied when sphericity was violated, but uncorrected degrees of freedom are reported for ease of interpretation.

For the old/new task during scanning, we computed percentage of correct responses and RTs to the correct responses. The design matrix contains one missing level. Trained birds consisted of $\mathrm{S}_{\mathrm{e}} \mathrm{S}_{\mathrm{t}} \mathrm{S}_{\mathrm{c}}, \mathrm{D}_{\mathrm{e}} \mathrm{S}_{\mathrm{t}} \mathrm{S}_{\mathrm{c}}, \mathrm{D}_{\mathrm{e}} \mathrm{D}_{\mathrm{t}} \mathrm{S}_{\mathrm{c}}$, and $\mathrm{D}_{\mathrm{e}} \mathrm{D}_{\mathrm{t}} \mathrm{D}_{\mathrm{c}}$ pairs. For the Novel birds, we had $\mathrm{S}_{\mathrm{e}} \mathrm{S}_{\mathrm{t}} \mathrm{S}_{\mathrm{c}}, \mathrm{D}_{\mathrm{e}} \mathrm{S}_{\mathrm{t}} \mathrm{S}_{\mathrm{c}}$, and $\mathrm{D}_{\mathrm{e}} \mathrm{D}_{t} \mathrm{D}_{\mathrm{c}}$ pairs but no $\mathrm{D}_{\mathrm{e}} \mathrm{D}_{t} \mathrm{~S}_{\mathrm{c}}$ pairs because this is a dissociation that is only present after training. We submitted the overlapping levels to a Training Type (trained, novel) $\times$ Pair Type $\left(\mathrm{S}_{\mathrm{e}} \mathrm{S}_{\mathrm{t}} \mathrm{S}_{\mathrm{c}}, \mathrm{D}_{\mathrm{e}} \mathrm{S}_{\mathrm{t}} \mathrm{S}_{\mathrm{c}}, \mathrm{D}_{\mathrm{e}} \mathrm{D}_{\mathrm{t}} \mathrm{D}_{\mathrm{c}}\right)$ ANOVA with repeated measures. This way, we established whether there was an effect of training and/or condition. Second, we performed paired $t$ tests to compare the pair types within the trained and novel birds with each other and we compared overlapping conditions between trained and novel bird pairs. The $t$ tests were two-tailed and not corrected for multiple comparisons. Greenhouse-Geisser corrections were applied when appropriate.

\section{RESULTS}

\section{Behavioral Data}

\section{Training}

During training, subjects made two-alternative category responses for four bird types from each of 16 levels of morphing (Figure 3A and B). Subjects categorized the bird types in three training sessions. Performance increased significantly over training sessions, $F(2,34)=39.03, p<$ .001 (see Figure 3A). Subjects' performance was already slightly above chance level during the first block of training, $t(17)=3.84, p<.005$. However, the first 40 trials of the first block were at chance level, $t(17)=0.34, p=n s$. Sub- jects were more accurate in categorizing birds with higher morph levels, $F(7,119)=132.984, p<.001$. Furthermore, the effect of morph level was highest in Session 3 and lowest in Session 1, as revealed by a significant interaction between morph level and training session, $F(14,238)=$ $3.98, p<.005$.

RTs decreased significantly over training sessions, $F(2,34)=10.47, p<.001$ (see Figure 3A). RTs were faster for birds consisting of higher morph levels, $F(7,119)=$ $34.16, p<.001$. The effect of morph level was greatest in Session 3 and lowest in Session 1, as revealed by a significant training session by morph level interaction, $F(14$, $238)=3.48, p<.01$.

At the end of training, in the third training session, categorical perception was established (see Figure 3B). The difference between the correctly assigned category labels is larger for pairs with a $10 \%$ difference that crossed the category boundary (45\% and 55\% morph levels) than for pairs with an equal distance, which were from the same side of the category boundary, 70\% and 80\% morph levels, $t(17)=18.95, p<.0001$, and with $60 \%$ and $70 \%$ morph levels, $t(17)=18.68, p<.0001$.

\section{Old/New Task}

During scanning, the subjects were presented with the birds, rapidly presented in pairs. Subjects performed an old/new task and indicated whether they remembered the second bird being present in the training session ("old") or not ("new"). Subjects had a relatively high rate of false alarms; they were biased to respond "old" to new bird types (see Figure 3C). This was confirmed by a low $d^{\prime}$ (.50 with $S E M=0.14)$.

We found that the task during scanning did not induce a category effect, but there was an effect of bird type on the behavior. The percentage of correct responses was significantly greater for trained than novel bird pairs, $F(1,17)=16.79, p<.005$, and differed significantly between the different pair types, $F(2,34)=11.41, p<.001$. The interaction between training and pair type was significant, $F(2,34)=3.53, p<.05$. For the trained bird pairs, the subjects responded "old" more often to birds from a pair that consisted of exemplars from the same bird type than for exemplars of different bird types: $\mathrm{S}_{\mathrm{e}} \mathrm{S}_{\mathrm{t}} \mathrm{S}_{\mathrm{c}}>\mathrm{D}_{\mathrm{e}} \mathrm{D}_{\mathrm{t}} \mathrm{D}_{\mathrm{c}}$, $t(17)=4.26, p<.001 ; \mathrm{D}_{\mathrm{e}} \mathrm{S}_{\mathrm{t}} \mathrm{S}_{\mathrm{c}}>\mathrm{D}_{\mathrm{e}} \mathrm{D}_{\mathrm{t}} \mathrm{D}_{\mathrm{c}}, t(17)=3.78$, $p<.001 ; \mathrm{S}_{\mathrm{e}} \mathrm{S}_{\mathrm{t}} \mathrm{S}_{\mathrm{c}}>\mathrm{D}_{\mathrm{e}} \mathrm{D}_{\mathrm{t}} \mathrm{S}_{\mathrm{c}}, t(17)=5.05, p<.001 ;$ and $\mathrm{D}_{\mathrm{e}} \mathrm{S}_{\mathrm{t}} \mathrm{S}_{\mathrm{c}}>\mathrm{D}_{\mathrm{e}} \mathrm{D}_{\mathrm{t}} \mathrm{S}_{\mathrm{c}}, t(17)=4.37, p<.001$. There was no significant difference between bird pairs containing exemplars from the same bird type, $\mathrm{S}_{\mathrm{e}} \mathrm{S}_{\mathrm{t}} \mathrm{S}_{\mathrm{c}}>\mathrm{D}_{\mathrm{e}} \mathrm{S}_{\mathrm{t}} \mathrm{S}_{\mathrm{c}}, t(17)=$ $0.00, p=n s$, and neither between bird pairs containing exemplars from different bird types, $\mathrm{D}_{\mathrm{e}} \mathrm{D}_{\mathrm{t}} \mathrm{D}_{\mathrm{c}}>\mathrm{D}_{\mathrm{e}} \mathrm{D}_{\mathrm{t}} \mathrm{S}_{\mathrm{c}}$, $t(17)=1.19, p=n s$.

The same pattern was observed for the RTs. RTs were significantly faster for trained than novel bird exemplars, $F(1,15)=8.16, p<.05$, and differed significantly between conditions, $F(2,30)=8.11, p<.01$. RTs were faster for bird pairs that contained bird exemplars from the same 


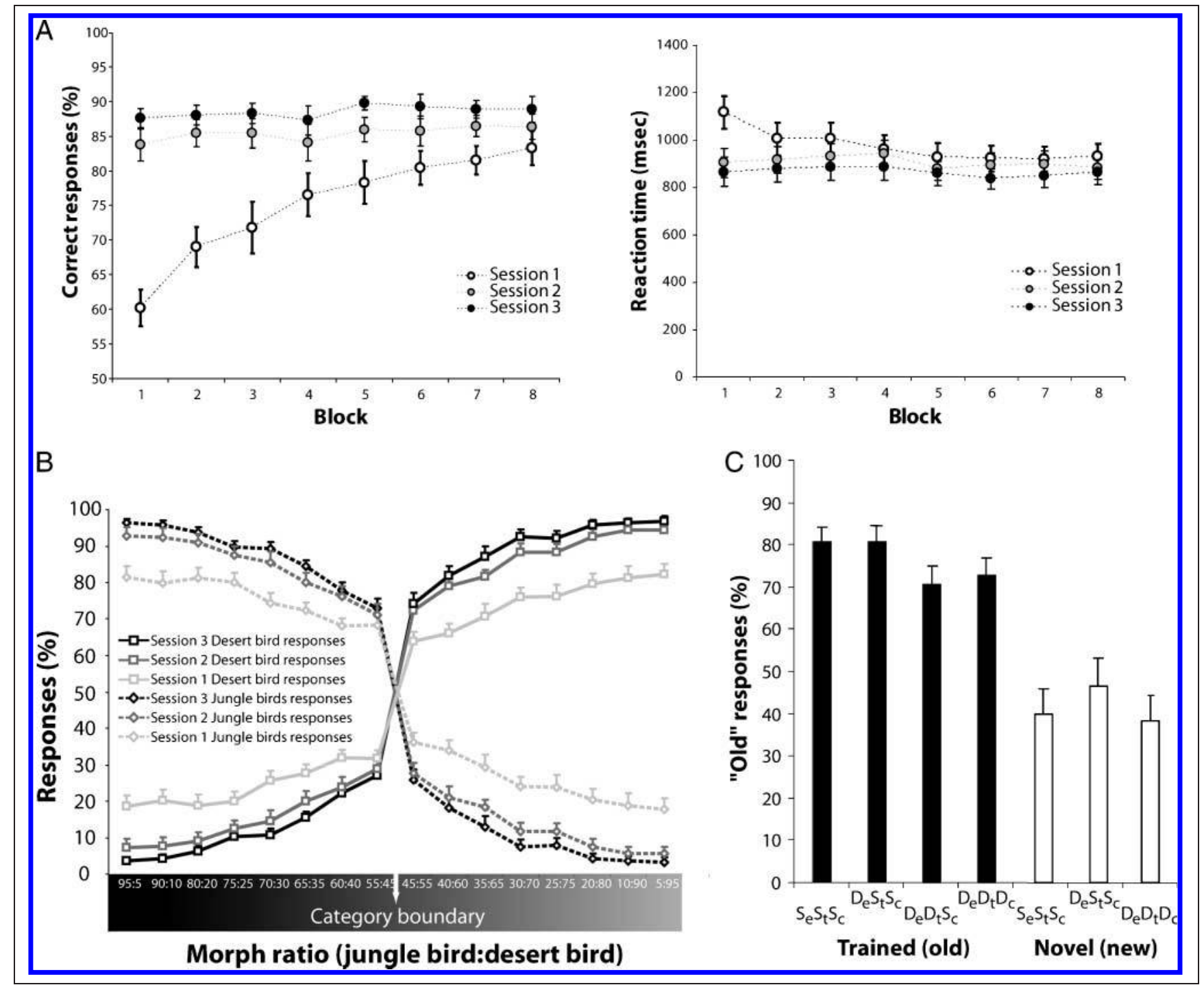

Figure 3. Behavioral results. (A) Results of categorization training. Plots present the percentage of correct responses and RTs for each block of training for all three training sessions. (B) The percentage of birds that were categorized ( $y$-axis) as either a desert bird (blue) or a jungle bird (red) is shown as a function of the 16 morph ratios between jungle and desert birds ( $x$-axis). (C) Results of the behavioral "old-new" task during scanning. Percentage of "hitsh and "false alarm" responses ( $y$-axis) is plotted as a function of pair type ( $x$-axis) for trained ("old") and novel birds ("new"). Error bars present the SEM.

bird type than for bird pairs consisting of exemplars from different bird types: $\mathrm{S}_{\mathrm{e}} \mathrm{S}_{\mathrm{t}} \mathrm{S}_{\mathrm{c}}<\mathrm{D}_{\mathrm{e}} \mathrm{D}_{\mathrm{t}} \mathrm{D}_{\mathrm{c}}, t(17)=4.10, p<$ $.001 ; \mathrm{S}_{\mathrm{e}} \mathrm{S}_{\mathrm{t}} \mathrm{S}_{\mathrm{c}}<\mathrm{D}_{\mathrm{e}} \mathrm{D}_{\mathrm{t}} \mathrm{S}_{\mathrm{c}}, t(17)=2.99, p<.01 ; \mathrm{D}_{\mathrm{e}} \mathrm{S}_{\mathrm{t}} \mathrm{S}_{\mathrm{c}}<$ $\mathrm{D}_{\mathrm{e}} \mathrm{D}_{\mathrm{t}} \mathrm{D}_{\mathrm{c}}, t(17)=4.68, p<.001$; and $\mathrm{D}_{\mathrm{e}} \mathrm{S}_{\mathrm{t}} \mathrm{S}_{\mathrm{c}}<\mathrm{D}_{\mathrm{e}} \mathrm{D}_{\mathrm{t}} \mathrm{S}_{\mathrm{c}}$, $t(17)=4.45, p<.001$. There was no difference in RTs for bird pairs containing exemplars from the same bird category, $\mathrm{S}_{\mathrm{e}} \mathrm{S}_{\mathrm{t}} \mathrm{S}_{\mathrm{c}}<\mathrm{D}_{\mathrm{e}} \mathrm{S}_{\mathrm{t}} \mathrm{S}_{\mathrm{c}}, t(17)=0.03, p=n s$, or bird pairs consisting exemplars from different bird types, $\mathrm{D}_{\mathrm{e}} \mathrm{D}_{\mathrm{t}} \mathrm{D}_{\mathrm{c}}<$ $\mathrm{D}_{\mathrm{e}} \mathrm{D}_{\mathrm{t}} \mathrm{S}_{\mathrm{c}}, t(17)=0.04, p=n s$.

\section{fMRI}

\section{Adaptation Effects}

We tested for adaptation of trained and novel birds separately by comparing $\mathrm{S}_{\mathrm{e}} \mathrm{S}_{\mathrm{t}} \mathrm{S}_{\mathrm{c}}$ with $\mathrm{D}_{\mathrm{e}} \mathrm{D}_{\mathrm{t}} \mathrm{D}_{\mathrm{c}}$ bird pairs. At $p<$
.05 (FDR-corrected), we found no areas that showed adaptation (i.e., less activity for $S_{e} S_{t} S_{c}$ than for $D_{e} D_{t} D_{c}$ birds pairs) for novel birds. Omitting the cluster threshold still showed no results. The trained birds, however, showed adaptation in bilateral occipito-temporal cortex, fusiform gyri, bilateral superior temporal sulci, bilateral precentral gyri, right inferior frontal gyrus, bilateral caudate nuclei, and bilateral intraparietal sulci (see Figure 4).

To increase power and to test whether there existed areas that showed adaptation for novel birds, we collapsed over trained and novel birds. Several cortical areas showed reduced activity for identical $\left(\mathrm{S}_{\mathrm{e}} \mathrm{S}_{\mathrm{t}} \mathrm{S}_{\mathrm{c}}\right.$ trained + novel $)$ pairs relative to pairs consisting of two different bird types $\left(\mathrm{D}_{\mathrm{e}} \mathrm{D}_{\mathrm{t}} \mathrm{D}_{\mathrm{c}}\right.$ trained + novel$)$, including bilateral occipitotemporal cortex, bilateral superior temporal sulci, bilateral precentral gyri, right inferior frontal gyrus, bilateral caudate 


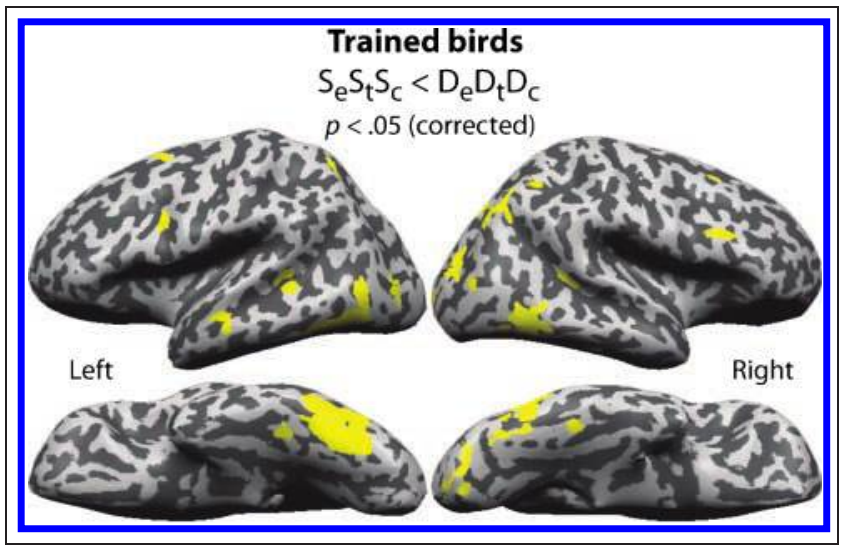

Figure 4. Brain regions showing adaptation following trained $S_{e} S_{t} S_{c}$ bird pairs $(p<.05$, corrected) presented on Talairach-normalized inflated left and right hemispheres. Top: lateral view; bottom: ventral views.

nuclei, and bilateral intraparietal sulci (see Figure 5). The mean beta weights (see Methods section) obtained for novel and trained birds separately for each of the pair types for several of these brain regions are shown in Figure 5. Beta weights from all regions were submitted to paired $t$ tests $(d f=17)$, in which the subject-averaged beta weights of $\mathrm{S}_{\mathrm{e}} \mathrm{S}_{\mathrm{t}} \mathrm{S}_{\mathrm{c}}$ and $\mathrm{D}_{\mathrm{e}} \mathrm{D}_{\mathrm{t}} \mathrm{D}_{\mathrm{c}}$ pairs were compared for trained and novel birds separately (see Table 1 ). We tested whether these areas showed a training-induced selectivity, that is, adaptation that is only present for trained bird types, or whether these areas are involved in general shape representation, that is, showing also adaptation for novel birds. In addition, we also tested if these areas showed category selectivity, that is, selectivity for birds belonging to the same category. The results confirm our previous analysis. As expected, all regions showed a significant adaptation effect for trained bird pairs that contained the same exemplars from the same bird type and the same category $\left(\mathrm{S}_{\mathrm{e}} \mathrm{S}_{\mathrm{t}} \mathrm{S}_{\mathrm{c}}\right)$ relative to bird pairs consisting of different exemplars from different bird types and different trained categories $\left(\mathrm{D}_{\mathrm{e}} \mathrm{D}_{\mathrm{t}} \mathrm{D}_{\mathrm{c}}\right)$. In addition, adaptation for novel bird pairs consisting of the same exemplars $\left(\mathrm{S}_{\mathrm{e}} \mathrm{S}_{\mathrm{t}} \mathrm{S}_{\mathrm{c}}\right)$ was present in left precentral gyrus, right middle frontal gyrus, and right intraparietal sulcus, and this adaptation effect was not significantly different from the adaptation to trained birds. In the occipitotemporal regions, no adaptation was present for novel bird pairs from the $S_{e} S_{t} S_{c}$ conditions; the adaptation effects for trained $\mathrm{S}_{\mathrm{e}} \mathrm{S}_{\mathrm{t}} \mathrm{S}_{\mathrm{c}}$ bird pairs were significantly greater than for novel $S_{e} S_{t} S_{c}$ bird pairs. The only area that showed adaptation for $D_{e} S_{t} S_{c}$ and $D_{e} D_{t} S_{c}$ for the trained bird types was the left anterior STS: $\mathrm{D}_{\mathrm{e}} \mathrm{S}_{\mathrm{t}} \mathrm{S}_{\mathrm{c}}, t(17)=2.39, p<.005 ; \mathrm{D}_{\mathrm{e}} \mathrm{D}_{\mathrm{t}} \mathrm{S}_{\mathrm{c}}$, $t(17)=3.18, p<.01$.

\section{Category Selectivity}

Although $\mathrm{S}_{\mathrm{e}} \mathrm{S}_{\mathrm{t}} \mathrm{S}_{\mathrm{c}}$ bird pairs inherently include both repetitions of the same bird type and category, of primary inter- est was whether bird pairs consisting of different exemplars and different bird types but still belonging to the same bird category $\left(\mathrm{D}_{\mathrm{e}} \mathrm{D}_{\mathrm{t}} \mathrm{S}_{\mathrm{c}}\right)$ would produce reduced activity in comparison to two birds from different categories $\left(\mathrm{D}_{\mathrm{e}} \mathrm{D}_{\mathrm{t}} \mathrm{D}_{\mathrm{c}}\right)$. To test directly for regions showing category selectivity, we used a conjunction analysis to find regions that showed adaptation to $S_{e} S_{t} S_{c}, D_{e} S_{t} S_{c}$, and $D_{e} D_{t} S_{c}$ bird pairs relative to $\mathrm{D}_{\mathrm{e}} \mathrm{D}_{\mathrm{t}} \mathrm{D}_{\mathrm{c}}$ bird pairs $\left[\left(\mathrm{S}_{\mathrm{e}} \mathrm{S}_{\mathrm{t}} \mathrm{S}_{\mathrm{c}}<\mathrm{D}_{\mathrm{e}} \mathrm{D}_{\mathrm{t}} \mathrm{D}_{\mathrm{c}}\right) \cap\left(\mathrm{D}_{\mathrm{e}} \mathrm{S}_{\mathrm{t}} \mathrm{S}_{\mathrm{c}}<\right.\right.$ $\left.\left.D_{e} D_{t} D_{c}\right) \cap\left(D_{e} D_{t} S_{c}<D_{e} D_{t} D_{c}\right)\right]$ (see Figure 6). These results confirmed the findings from our ROI analysis. Two regions in the left STS showed category selectivity. They showed adaptation for birds from the $S_{e} S_{t} S_{c}, D_{e} S_{t} S_{c}$, and $\mathrm{D}_{\mathrm{e}} \mathrm{D}_{\mathrm{t}} \mathrm{S}_{\mathrm{c}}$ condition relative to birds from the $\mathrm{D}_{\mathrm{e}} \mathrm{D}_{t} \mathrm{D}_{\mathrm{c}}$ condition. In the left STS, responses were smaller for $\mathrm{S}_{\mathrm{e}} \mathrm{S}_{\mathrm{t}} \mathrm{S}_{\mathrm{C}}$, $t(17)=3.50, p<.005, \mathrm{D}_{\mathrm{e}} \mathrm{S}_{\mathrm{t}} \mathrm{S}_{\mathrm{c}}, t(17)=2.34, p<.05$, and $\mathrm{D}_{\mathrm{e}} \mathrm{D}_{\mathrm{t}} \mathrm{S}_{\mathrm{c}}$ bird pairs, $t(17)=2.96, p<.01$, compared with $\mathrm{D}_{\mathrm{e}} \mathrm{D}_{\mathrm{t}} \mathrm{D}_{\mathrm{c}}$ bird pairs. In the left anterior temporal sulcus, responses were also smaller for $\mathrm{S}_{\mathrm{e}} \mathrm{S}_{\mathrm{t}} \mathrm{S}_{\mathrm{c}}, t(17)=2.43, p<$ $.05, \mathrm{D}_{\mathrm{e}} \mathrm{S}_{\mathrm{t}} \mathrm{S}_{\mathrm{c}}, t(17)=2.83, p<.05$, and $\mathrm{D}_{\mathrm{e}} \mathrm{D}_{\mathrm{t}} \mathrm{S}_{\mathrm{c}}$ bird pairs, $t(17)=3.51, p<.005$, than for $\mathrm{D}_{\mathrm{e}} \mathrm{D}_{\mathrm{t}} \mathrm{D}_{\mathrm{c}}$ bird pairs. In addition, we investigated whether the adaptation scores differed between the different pair types. We found no differences in adaptation scores between the different conditions, left STS: $\mathrm{S}_{\mathrm{e}} \mathrm{S}_{\mathrm{t}} \mathrm{S}_{\mathrm{c}}>\mathrm{D}_{\mathrm{e}} \mathrm{S}_{\mathrm{t}} \mathrm{S}_{\mathrm{c}}, t(17)=0.37, p=$ $n s ; \mathrm{S}_{\mathrm{e}} \mathrm{S}_{\mathrm{t}} \mathrm{S}_{\mathrm{c}}>\mathrm{D}_{\mathrm{e}} \mathrm{D}_{\mathrm{t}} \mathrm{S}_{\mathrm{c}}, t(17)=0.39, p=n s$; and $\mathrm{D}_{\mathrm{e}} \mathrm{S}_{\mathrm{t}} \mathrm{S}_{\mathrm{c}}>$ $\mathrm{D}_{\mathrm{e}} \mathrm{D}_{\mathrm{t}} \mathrm{S}_{\mathrm{c}}, t(17)=0.02, p=n s$; left anterior temporal sulcus: $\mathrm{S}_{\mathrm{e}} \mathrm{S}_{\mathrm{t}} \mathrm{S}_{\mathrm{c}}>\mathrm{D}_{\mathrm{e}} \mathrm{S}_{\mathrm{t}} \mathrm{S}_{\mathrm{c}}, t(17)=0.30, p=n s ; \mathrm{S}_{\mathrm{e}} \mathrm{S}_{\mathrm{t}} \mathrm{S}_{\mathrm{c}}>\mathrm{D}_{\mathrm{e}} \mathrm{D}_{\mathrm{t}} \mathrm{S}_{\mathrm{c}}$, $t(17)=0.35, p=n s$; and $\mathrm{D}_{\mathrm{e}} \mathrm{S}_{\mathrm{t}} \mathrm{S}_{\mathrm{c}}>\mathrm{D}_{\mathrm{e}} \mathrm{D}_{\mathrm{t}} \mathrm{S}_{\mathrm{c}}, t(17)=0.81$, $p=n s$.

No adaptation effect was found for novel birds; responses to novel $S_{e} S_{t} S_{c}$ and $D_{e} S_{t} S_{c}$ bird pairs did not differ in left STS, $\mathrm{S}_{\mathrm{e}} \mathrm{S}_{\mathrm{t}} \mathrm{S}_{\mathrm{c}}, t(17)=0.15, p=n s$ and $\mathrm{D}_{\mathrm{e}} \mathrm{S}_{\mathrm{t}} \mathrm{S}_{\mathrm{c}}$, $t(17)=0.08, p=n s$, and left anterior temporal sulcus, $\mathrm{S}_{\mathrm{e}} \mathrm{S}_{\mathrm{t}} \mathrm{S}_{\mathrm{c}}, t(17)=1.04, p=n s$ and $\mathrm{D}_{\mathrm{e}} \mathrm{S}_{\mathrm{t}} \mathrm{S}_{\mathrm{c}}, t(17)=0.58$, $p=n s$.

\section{DISCUSSION}

In the present fMRI study, we investigated the neural mechanisms that underlie experience-related formation of object categories. Subjects learned to categorize four artificial bird types into two bird categories. Behavioral training results showed that after 3 days of training, subjects were indeed successful in categorizing the birds. One day after training, subjects were scanned using a rapid fMRI adaptation paradigm. We used the adaptation approach to investigate changes in neural tuning as a function of category learning. We hypothesized that category training would induce neurons in the occipito-temporal cortex and the STS to display selectivity for trained but not for novel bird stimuli. This is indeed what we found.

In the fusiform gyrus, adaptation occurred for identical exemplars of trained bird types but not for identical exemplars of novel bird types. Similar adaptation effects were found in the bilateral lateral occipital gyri. These results show that training to categorize birds induces 


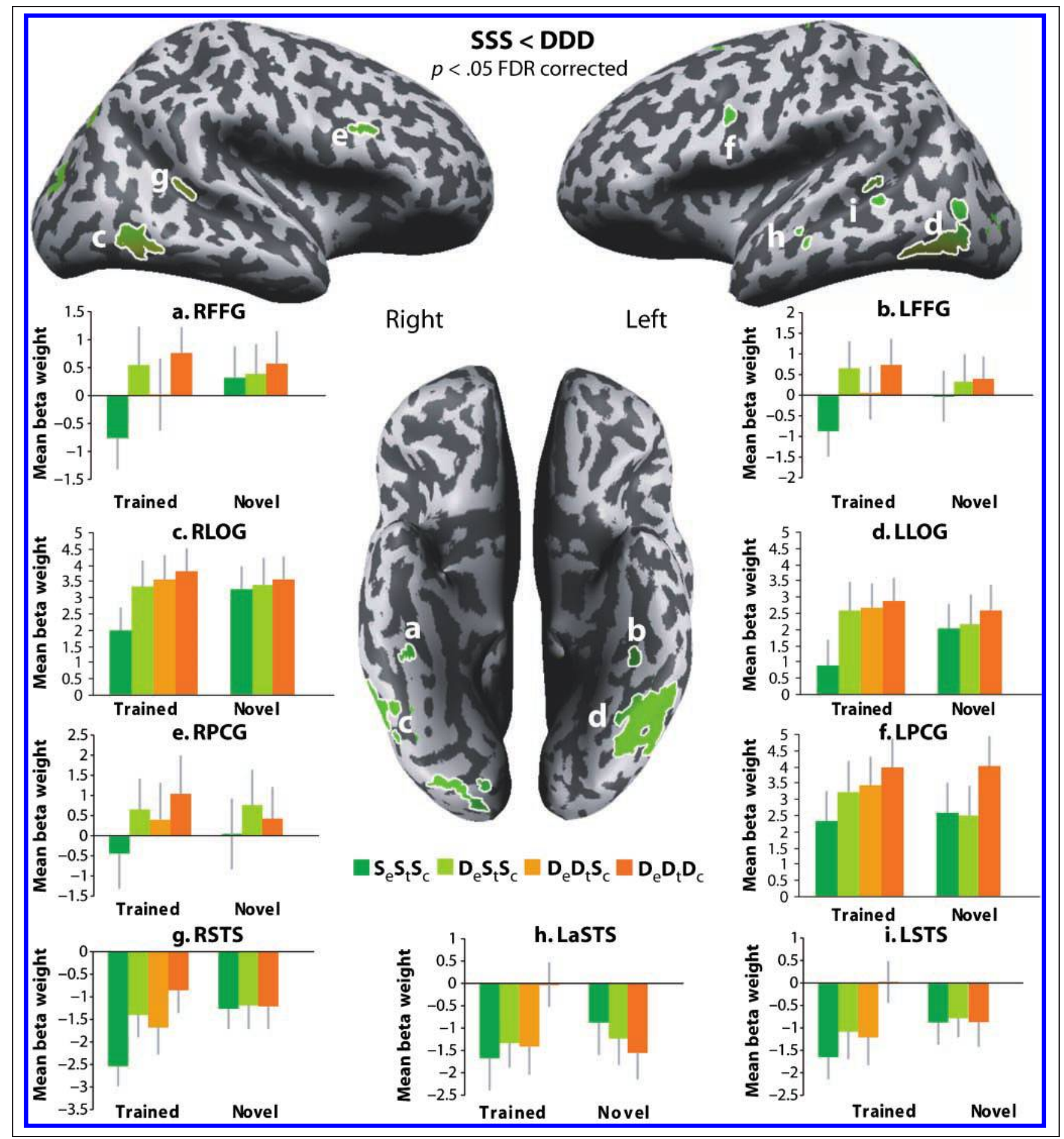

Figure 5. Brain regions showing adaptation following $\mathrm{S}_{\mathrm{e}} \mathrm{S}_{\mathrm{t}} \mathrm{S}_{\mathrm{c}}$ bird pairs (trained and novel birds collapsed, $p<.05$, corrected) presented on Talairach-normalized inflated left and right hemispheres. Top: lateral view; bottom: ventral view. Histograms present mean beta weights for $\mathrm{S}_{\mathrm{e}} \mathrm{S}_{\mathrm{t}} \mathrm{S}_{\mathrm{c}}$ (dark green), $\mathrm{D}_{\mathrm{e}} \mathrm{S}_{\mathrm{t}} \mathrm{S}_{\mathrm{c}}$ (light green), $\mathrm{D}_{\mathrm{e}} \mathrm{D}_{\mathrm{t}} \mathrm{S}_{\mathrm{c}}$ (orange), and $\mathrm{D}_{\mathrm{e}} \mathrm{D}_{\mathrm{t}} \mathrm{D}_{\mathrm{c}}$ (dark orange) bird pairs for both novel and trained bird types ( $x$-axis). LFFG $=$ left fusiform gyrus (Talairach coordinates of center of mass: $-36,-41,-19) ;$ RFFG $=$ right fusiform gyrus $(37,-38,-20)$; LLOG $=$ left lateral occipital gyrus $(-37,-66,-9) ;$ RLOG $=$ right lateral occipital gyrus $(44,-59,-10)$; LPCG = left precentral gyrus $(-40,-3,-30)$; RPCG = right precentral gyrus $(47,12,29)$; LaSTS = left anterior STS $(-55,-14,-9)$; LSTS = left STS $(-47,-41,6) ;$ RSTS = right STS (44, -35, 9).

neural sensitivity to small shape changes, whereas for novel birds, no differential neural responses between two similar looking exemplars of the same bird type were observed. These results are in line with our previous fMRI results on the involvement of the right fusiform gyrus in category formation (van der Linden et al., 2008). We found that after visual category training, responses in the right fusiform gyrus were selectively increased for bird 
Table 1. Regions Showing an Adaptation Effect for Trained Bird Pairs Consisting of the Same Exemplars $\left(\mathrm{S}_{\mathrm{e}} \mathrm{S}_{\mathrm{t}} \mathrm{S}_{\mathrm{c}}\right)$

\begin{tabular}{|c|c|c|c|c|c|c|c|c|}
\hline Anatomical Description & $B A$ & $x$ & $y$ & $z$ & $m m^{3}$ & t Average & Trained $S_{e} S_{t} S_{c}<D_{e} D_{t} D_{c}$ & Novel $S_{e} S_{t} S_{c}<D_{e} D_{t} D_{c}$ \\
\hline \multirow[t]{2}{*}{ L precentral G } & 4 & -21 & -20 & 53 & 468 & 3.82 & $4.57 * * *$ & $1.02^{n s}$ \\
\hline & $4 / 6$ & -40 & -3 & 30 & 1350 & 3.28 & $3.20 * *$ & $2.63 *$ \\
\hline R precentral G & $4 / 6$ & 30 & -16 & 46 & 98 & 3.50 & $4.63 * * *$ & $1.99^{n s}$ \\
\hline $\mathrm{L}$ intraparietal S & 7 & -24 & -55 & 51 & 244 & 3.59 & $4.03 * * *$ & $1.95^{n s}$ \\
\hline $\mathrm{R}$ intraparietal $\mathrm{S}$ & 7 & 27 & -67 & 39 & 1774 & 3.58 & $4.55 * * *$ & $2.27^{*}$ \\
\hline L supramarginal G & 40 & -34 & -32 & 34 & 106 & 3.49 & $4.27 * * *$ & $1.65^{n s}$ \\
\hline R superior frontal $G$ & 8 & 4 & 22 & 45 & 269 & 3.48 & $2.91 * *$ & $0.12^{n s}$ \\
\hline $\mathrm{R}$ middle frontal $\mathrm{G}$ & $4 / 6$ & 29 & 14 & 43 & 316 & 3.65 & $3.21 * *$ & $2.79 *$ \\
\hline $\mathrm{R}$ inferior frontal $\mathrm{G}$ & 44 & 47 & 12 & 29 & 1233 & 3.23 & $2.94 * *$ & $0.82^{n s}$ \\
\hline $\mathrm{R}$ caudate nucleus & & 18 & -14 & 28 & 160 & 3.43 & $4.30 * * *$ & $0.53^{n s}$ \\
\hline L caudate nucleus & & -15 & -21 & 24 & 159 & 3.51 & $5.24 * * *$ & $0.10^{n s}$ \\
\hline R superior temporal S & $22 / 42$ & 44 & -35 & 9 & 2262 & 3.36 & $4.71 * * *$ & $0.12^{n s}$ \\
\hline L superior temporal S & 22 & -47 & -41 & 6 & 1039 & 3.38 & $3.52 * *$ & $0.02^{n s}$ \\
\hline $\mathrm{L}$ ant superior temporal $\mathrm{S}$ & 21 & -55 & -14 & -9 & 1223 & 3.22 & $2.66^{*}$ & $1.50^{n s}$ \\
\hline $\mathrm{R}$ middle occipital $\mathrm{G}$ & 19 & 25 & -81 & 12 & 621 & 3.60 & $5.22 * * *$ & $0.30^{n s}$ \\
\hline Cuneus & 18 & 4 & -79 & 8 & 4097 & 3.65 & $3.28 * *$ & $0.02^{n s}$ \\
\hline L lingual G & 19 & -9 & -46 & 3 & 1546 & 3.69 & $4.34 * * *$ & $1.02^{n s}$ \\
\hline R lingual G & 19 & 8 & -55 & -2 & 489 & 3.56 & $3.66 * *$ & $0.52^{n s}$ \\
\hline R lingual $G$ & 19 & 19 & -83 & -12 & 1378 & 3.64 & $3.50 * *$ & $0.96^{n s}$ \\
\hline L lateral occipital G & 37 & -37 & -66 & -9 & 10149 & 3.58 & $5.43 * * *$ & $1.18^{n s}$ \\
\hline R lateral occipital G & 37 & 44 & -59 & -10 & 5181 & 3.34 & $5.09 * * *$ & $0.58^{n s}$ \\
\hline L fusiform $G$ & $36 / 37$ & -36 & -41 & -19 & 843 & 3.36 & $6.24 * * *$ & $1.01^{n s}$ \\
\hline R fusiform $G$ & $36 / 37$ & 37 & -38 & -20 & 520 & 3.29 & $4.22 * * *$ & $0.58^{n s}$ \\
\hline
\end{tabular}

Mean Talairach coordinates, volume in $\mathrm{mm}^{3}$, and averaged $t$ values for regions showing an adaptation effect for trained $\mathrm{S}_{\mathrm{e}} \mathrm{S}_{\mathrm{t}} \mathrm{S}_{\mathrm{c}}$ bird types at $p<.05$ (corrected). In addition, we present $t$ values obtained in a random effects ROI analysis $(d f=17)$ on the subject-averaged beta weights comparing bird pairs consisting of the same exemplars with bird pairs consisting of birds from different categories $\left(\mathrm{S}_{\mathrm{e}} \mathrm{S}_{\mathrm{t}} \mathrm{S}_{\mathrm{c}}<\mathrm{D}_{\mathrm{e}} \mathrm{D}_{\mathrm{t}} \mathrm{D}_{\mathrm{c}}\right)$ for both trained and novel birds. Ant $=$ anterior; $\mathrm{L}=$ left; $\mathrm{R}=$ right; $\mathrm{G}=$ gyrus; $\mathrm{S}=$ sulcus.

$* p<.05$.

$* * p<.01$.

$* * * p<.001$.

types for which a discrete category boundary was established. Importantly, this increase was not observed for visually similar birds to which subjects were exposed during training but for which no category boundary was learned. In addition, we found that the increase was linearly related to the distance to the category boundary: the further away from the boundary, the higher the responses. These results suggested that visual category training leads to an increase in selectivity for visual features that are relevant for categorization. The present adaptation results provide more specific evidence for this hypothesis. Category training induced an increase in neural selectivity for fine-grained visual object features. The increased selectivity might be attributed to an increase in neural tuning to the visual features that are relevant for categorization.

Our finding is different from the finding of Jiang et al. (2007), who found no adaptation in the middle fusiform gyrus for pairs of cars that consisted of the same exemplars during a shape-displacement task, neither before nor after training. However, our results agree with other fMRI studies that found an effect of experience on response strength of the right middle fusiform gyrus to objects of expertise (Xu, 2005; Rhodes et al., 2004; Gauthier et al., 2000) or to novel objects that subjects trained with (Weisberg et al., 2007; Gauthier et al., 1999). In addition, our results are in line with electrophysiological recordings from the 
Figure 6. Brain regions showing a category-selective response $(p<.05$, corrected $)$ are presented on coronal slices corresponding to the location of regions $\mathrm{h}$ and $\mathrm{i}$ in Figure 5 . The graphs present the mean beta weights from the left STS (Talairach coordinates of center of mass: $-46,-40,6)$ and left anterior STS $(-59,-16,-11)$.

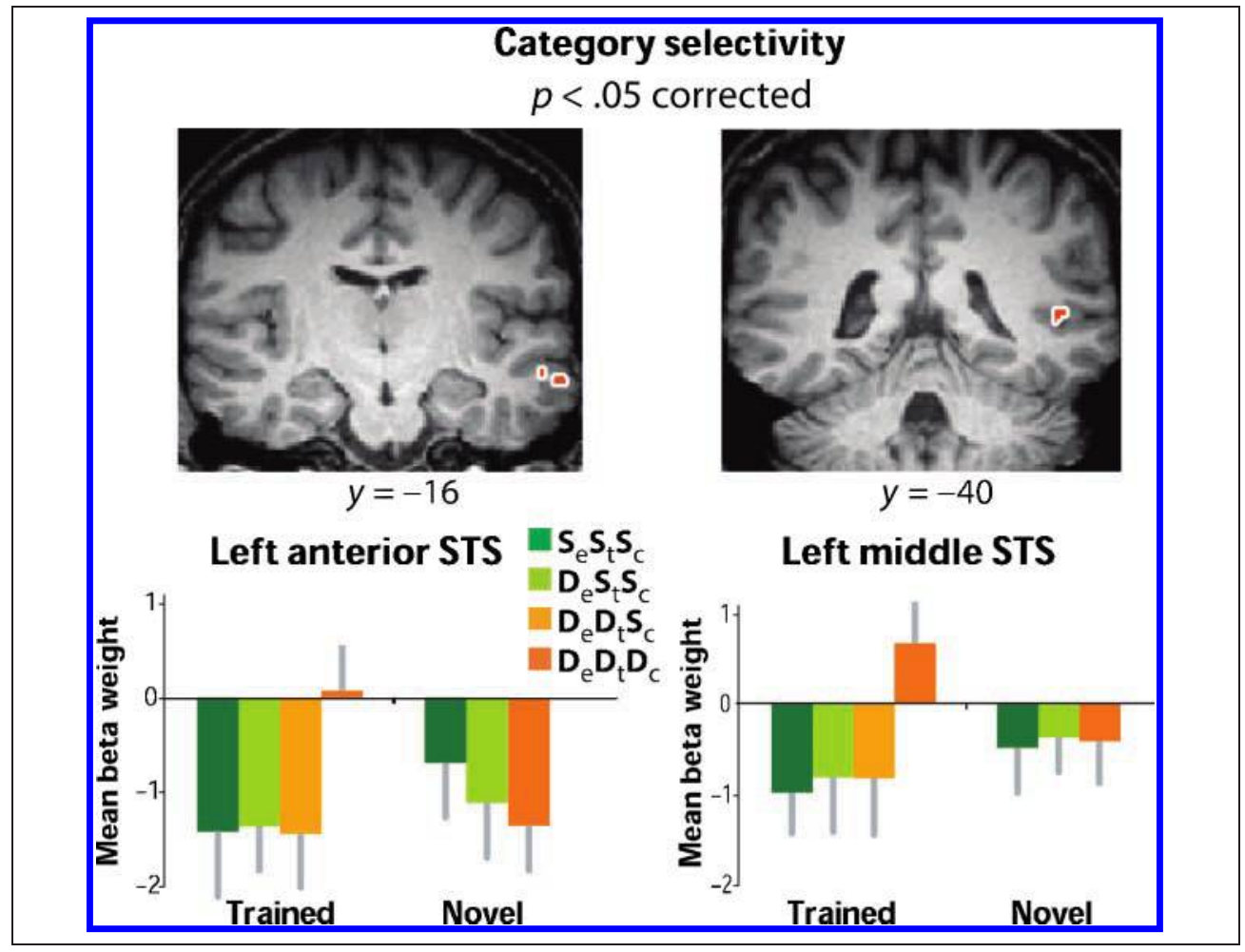

inferior temporal cortex in monkeys suggesting that object category formation is mediated by a learning-induced neuronal stimulus selectivity (Freedman, Riesenhuber, Poggio, \& Miller, 2003, 2006).

The fusiform gyrus showed adaptation only to the repetition of identical trained birds. A relatively small shape change (20\%) led to a release of adaptation. This indicates that the right middle fusiform gyrus shows a high level of perceptual specificity. This is in line with other fMRI adaptation studies showing that the fusiform gyrus is narrowly tuned for shapes and shows very little invariance (Gilaie-Dotan \& Malach, 2007; Jiang et al., 2006). Future research should be able to elucidate which amount of shape change will still give rise to an adapted response and at which level a release of adaptation takes place. Such an investigation, as has been used for face stimuli (GilaieDotan \& Malach, 2007; Loffler et al., 2005), could potentially give more information on the underlying neuronal representation of nonface objects.

In accordance with Jiang et al. (2007), we found adaptation for identical stimuli in the lateral occipital gyrus. This observation held for trained but not for novel birds, in line with the finding of Jiang et al. that there was no adaptation for identical cars in a pretraining scan. Just like Jiang et al., we found evidence for narrow shape tuning in the lateral occipital gyrus. A small change in the stimulus leads to a release of adaptation. The lateral occipital gyrus has also been found to show an increase in response strength after discrimination training with novel objects (Op de Beeck et al., 2006). Both the fusiform and the lat- eral occipital gyrus showed narrow shape tuning and showed no effect when two exemplars that belonged to the same bird type or category were presented. We found no other areas that displayed sensitivity to the repetition of two exemplars from the same perceptual bird type. Possibly, the training procedure was too short to induce such a category effect in the occipito-temporal areas or the training did not facilitate the learning of the category boundary between perceptual bird types. Jiang et al. do not report having investigated brain regions that show sensitivity to car type.

Importantly, we did find a region that responded in a category-specific manner in the absence of an explicit categorization task. The task we used had the function to keep subjects attentive. Without such a task, the adaptation effects might have been more difficult or impossible to detect. In this general sense, it is possible that the tasks had an influence on STS adaptation. Crucially, however, the task did not require application of the trained categories; hence, the fact that we observed effects of the trained categories cannot be attributed to a task requirement to use these categories as in the study by Jiang et al. (2007). Our task alone cannot explain that the left STS showed adaptation when two birds from the same trained category were presented but release from adaptation for the trained bird types for objects belonging to different categories. This dissociation could also not be explained by perceptual similarities or dissimilarities because the physical difference between birds from the same and opposite sides of the category boundary was equal. 
This finding provides evidence for the STS being involved in the representation of category information. Neuroimaging studies have shown that regions in the STS are responsive to biological stimuli such as faces, human bodies (Kanwisher, McDermott, \& Chun, 1997; Puce, Allison, Gore, \& McCarthy, 1995), and animals (Chao et al., 1999, 2002). For face stimuli, the STS has been found to respond in a category-selective way to identity (Rotshtein et al., 2005) and emotions (Furl, van Rijsbergen, Treves, Friston, \& Dolan, 2007). Therefore, the role of the STS in representing category information might be limited to biologically relevant stimuli. This would also explain why Jiang et al. (2007), who used nonnatural stimuli, found no adaptation effect for cars belonging to the same category. Alternatively, our training paradigm might also have led to a different encoding of the category information than the paradigm of Jiang et al. In our experiment, subjects learned categories by labeling birds, whereas in the experiment of Jiang et al., subjects learned by discrimination. The emphasis in discrimination is on the differences that exist between exemplars by directly comparing one exemplar to the other. Discrimination is relative (always compared with another object) whereas labeling is absolute ("desert" or "jungle"). Labeling category members facilitates the formation of associations between different exemplars within a category. The STS has been found to be involved in associating familiar sounds and shapes to facilitate cross-modal object representations (Hein et al., 2007; Beauchamp, Lee, Argall, \& Martin, 2004). Moreover, the STS has been suggested to play an important role in associative learning, linking different types of stimuli regardless of the modality (Tanabe, Honda, \& Sadato, 2005).

In the study of Jiang et al. (2007), the pFC responded in a category-selective manner, but only when subjects performed an explicit categorization task. Using intracranial recordings in monkeys, it has also been shown that the $\mathrm{pFC}$ is involved in categorization (Freedman, Riesenhuber, Poggio, \& Miller, 2001) and more specifically that the pFC is involved in explicit category decisions based on functional or behavioral relevance (Freedman et al., 2003). In the present study, using an old-new task, we found no category selectivity in the pFC, which confirms that the pFC may only be involved during active categorization.

We propose that the model for perceptual categorization as outlined by Jiang et al. (2007) could be extended with our data so that it includes conceptual categorization as well. As a result of training, the occipito-temporal cortex becomes sensitive to those features that are relevant for perceptual categorization. This is also confirmed by monkey electrophysiological recordings (Sigala \& Logothetis, 2002), where neurons became more sensitive to features relevant for categorization compared with features that were irrelevant for categorization. This narrow shape tuning allows for discrimination between highly similar objects but does not necessarily imply a category-selective representation. Categorization of objects extends beyond their physical differences in appearance and takes into account those features that are common in a category. The STS seems to be a candidate area to fulfill this role within the model. We found a category-selective response in the STS for stimuli that subjects learned to categorize. The STS is located on the border of visual and auditory association areas and receives input from visual as well as auditory cortex. The STS is widely regarded as a multisensory binding site. Recently, Hocking and Price (2008) concluded that the STS is involved in conceptual matching of stimuli regardless of their modality. Although our results are limited to the visual modality alone, they suggest that the STS is involved in conceptually linking different objects within a category allowing for true category specificity that extends beyond mere physical similarities of objects.

Jiang et al. (2007) propose that within their model, the pFC receives input from the occipito-temporal cortex and is involved in explicit category decisions. We cannot confirm this with our data, but monkey electrophysiological recordings also support this role for the pFC (Freedman et al., 2001, 2003; Freedman, Riesenhuber, Poggio, \& Miller, 2002). Jiang et al. (2007) also speculate that the pFC could exert a top-down influence on the responses in the occipitotemporal cortex. Modeling studies also suggest that the $\mathrm{pFC}$ might be involved during learning by having a top-down influence that enhances the selectivity of the neurons in the occipito-temporal cortex encoding the behaviorally relevant features of the stimuli (Szabo et al., 2006; Rougier, Noelle, Braver, Cohen, \& O’Reilly, 2005).

To conclude, adaptation effects in the occipito-temporal cortex, that is, the fusiform and lateral occipital gyrus, showed that these regions are very sensitive to perceptual stimulus differences. This suggests that neurons in the occipito-temporal cortex are narrowly tuned to specific object features and do not generalize across different objects from the same category. Moreover, this sensitivity is training induced, it arose as a result of experience with the birds and was not present for very similar novel birds. In addition, we found neuronal populations in STS to show a high level of invariance to perceptual dissimilarities between birds, displaying a selective response to different category members. This indicates that neurons in the STS formed associations between different stimuli and generalized across objects within a category. Together, the occipito-temporal cortex and the STS have the properties suitable for a system that can both generalize across stimuli and discriminate between them.

\section{Acknowledgments}

This research was supported by an NWO grant 400-03-338. the authors thank Armin Heinecke, Rainer Goebel, and Fabrizio Esposito for statistical advice.

Reprint requests should be sent to Marieke van der Linden, P.O. Box 9101, 6500 HB Nijmegen, The Netherlands, or via e-mail: mail@mariekevanderlinden.com. 


\section{REFERENCES}

Andrews, T. J., \& Ewbank, M. P. (2004). Distinct representations for facial identity and changeable aspects of faces in the human temporal lobe. Neuroimage, 23, 905-913.

Beauchamp, M. S., Lee, K. E., Argall, B. D., \& Martin, A. (2004). Integration of auditory and visual information about objects in superior temporal sulcus. Neuron, 41, 809-823.

Boynton, G. M., Engel, S. A., Glover, G. H., \& Heeger, D. J. (1996). Linear systems analysis of functional magnetic resonance imaging in human V1. Journal of Neuroscience, 16, 4207-4221.

Chao, L. L., Haxby, J. V., \& Martin, A. (1999). Attribute-based neural substrates in temporal cortex for perceiving and knowing about objects. Nature Neuroscience, 2 , 913-919.

Chao, L. L., Weisberg, J., \& Martin, A. (2002). Experience-dependent modulation of category-related cortical activity. Cerebral Cortex, 12, 545-551.

Cohen Kadosh, R., Cohen Kadosh, K., Kaas, A., Henik, A., \& Goebel, R. (2007). Notation-dependent and -independent representations of numbers in the parietal lobes. Neuron. 53, 307-314.

Epstein, R., Graham, K. S., \& Downing, P. E. (2003). Viewpoint-specific scene representations in human parahippocampal cortex. Neuron, 37, 865-876.

Ewbank, M. P., Schluppeck, D., \& Andrews, T. J. (2005). fMR-adaptation reveals a distributed representation of inanimate objects and places in human visual cortex. Neuroimage, 28, 268-279.

Freedman, D. J., Riesenhuber, M., Poggio, T., \& Miller, E. K. (2001). Categorical representation of visual stimuli in the primate prefrontal cortex. Science, 291, 312-316.

Freedman, D. J., Riesenhuber, M., Poggio, T., \& Miller, E. K. (2002). Visual categorization and the primate prefrontal cortex: Neurophysiology and behavior. Journal of Neurophysiology, 88, 929-941.

Freedman, D. J., Riesenhuber, M., Poggio, T., \& Miller, E. K. (2003). A comparison of primate prefrontal and inferior temporal cortices during visual categorization. Journal of Neuroscience, 23, 5235-5246.

Freedman, D. J., Riesenhuber, M., Poggio, T., \& Miller, E. K. (2006). Experience-dependent sharpening of visual shape selectivity in inferior temporal cortex. Cerebral Cortex. 16, 1631-1644.

Furl, N., van Rijsbergen, N. J., Treves, A., Friston, K. J., \& Dolan, R. J. (2007). Experience-dependent coding of facial expression in superior temporal sulcus. Proceedings of the National Academv of Sciences. U.S.A., 104, 13485-13489.

Gauthier, I., Skudlarski, P., Gore, J. C., \& Anderson, A. W. (2000). Expertise for cars and birds recruits brain areas involved in face recognition. Nature Neuroscience, 3, 191-197.

Gauthier, I., Tarr, M. J., Anderson, A. W., Skudlarski, P., \& Gore, J. C. (1999). Activation of the middle fusiform "face area" increases with expertise in recognizing novel objects. Nature Neuroscience, 2, 568-573.

Gilaie-Dotan, S., \& Malach, R. (2007). Sub-exemplar shape tuning in human face-related areas. Cerebral Cortex, 17, 325-338.

Grill-Spector, K., Henson, R., \& Martin, A. (2006). Repetition and the brain: Neural models of stimulus-specific effects. Trends in Cognitive Sciences, 10, 14-23.
Grill-Spector, K., Kushnir, T., Edelman, S., Avidan, G., Itzchak, Y., \& Malach, R. (1999). Differential processing of objects under various viewing conditions in the human lateral occipital complex. Neuron, 24, 187-203.

Grill-Spector, K., \& Malach, R. (2001). fMR-adaptation: A tool for studying the functional properties of human cortical neurons. Acta Psychologica, 107, 293-321.

Hein, G., Doehrmann, O., Muller, N. G., Kaiser, J., Muckli, L., \& Naumer, M. J. (2007). Object familiarity and semantic congruency modulate responses in cortical audiovisual integration areas. Journal of Neuroscience 27, 7881-7887.

Hocking, J., \& Price, C. J. (2008). The role of the posterior superior temporal sulcus in audiovisual processing. Cerebral Cortex, 18, 2439-2449.

Jiang, X., Bradley, E., Rini, R. A., Zeffiro, T., VanMeter, J., \& Riesenhuber, M. (2007). Categorization training results in shape- and category-selective human neural plasticity. Neuron, 53, 891-903.

Jiang, X., Rosen, E., Zeffiro, T., Vanmeter, J., Blanz, V., \& Riesenhuber, M. (2006). Evaluation of a shape-based model of human face discrimination using fMRI and behavioral techniques. Neuron, 50, 159-172.

Kanwisher, N., McDermott, J., \& Chun, M. M. (1997). The fusiform face area: A module in human extrastriate cortex specialized for face perception. Journal of Neuroscience, 17, 4302-4311.

Loffler, G., Yourganov, G., Wilkinson, F., \& Wilson, H. R. (2005). fMRI evidence for the neural representation of faces. Nature Neuroscience, 8, 1386-1390.

Mareschal, D., \& Quinn, P. C. (2001). Categorization in infancy. Trends in Cognitive Sciences, 5, 443-450.

Moore, C. D., Cohen, M. X., \& Ranganath, C. (2006). Neural mechanisms of expert skills in visual working memory. Journal of Neuroscience, 26, 11187-11196.

Nichols, T., Brett, M., Andersson, J., Wager, T., \& Poline, J. B. (2005). Valid conjunction inference with the minimum statistic. Neuroimage, 25, 653-660.

Op de Beeck, H. P., Baker, C. I., DiCarlo, J. J., \& Kanwisher, N. G. (2006). Discrimination training alters object representations in human extrastriate cortex. Lournal of Neuroscience, 26, 13025-13036.

Pourtois, G., Schwartz, S., Seghier, M. L., Lazeyras, F., \& Vuilleumier, P. (2005). View-independent coding of face identity in frontal and temporal cortices is modulated by familiarity: An event-related fMRI study. Neuroimage 24, 1214-1224.

Puce, A., Allison, T., Gore, J. C., \& McCarthy, G. (1995). Face-sensitive regions in human extrastriate cortex studied by functional MRI. Journal of Neurophysiology, 74, 1192-1199.

Rhodes, G., Byatt, G., Michie, P. T., \& Puce, A. (2004). Is the fusiform face area specialized for faces, individuation, or expert individuation? Journal of Cognitive Neuroscience. 16, 189-203.

Rotshtein, P., Henson, R. N., Treves, A., Driver, J., \& Dolan, R. J. (2005). Morphing Marilyn into Maggie dissociates physical and identity face representations in the brain. Nature Neuroscience, 8, 107-113.

Rougier, N. P., Noelle, D. C., Braver, T. S., Cohen, J. D., \& O'Reilly, R. C. (2005). Prefrontal cortex and flexible cognitive control: Rules without symbols. Proceedings of the National Academv of Sciences. U.S.A., 102, 7338-7343.

Sigala, N., \& Logothetis, N. K. (2002). Visual categorization shapes feature selectivity in the primate temporal cortex. Nature, 415, 318-320. 
Szabo, M., Stetter, M., Deco, G., Fusi, S., Giudice, P., \& Mattia, M. (2006). Learning to attend: Modeling the shaping of selectivity in infero-temporal cortex in a categorization task. Biological Cubernetics, 94, 351-365.

Talairach, J., \& Tournoux, P. (1988). Co-planar stereotaxic atlas of the buman brain: 3-Dimensional proportional system: An approach to medical cerebral imaging. New York: Thieme.

Tanabe, H. C., Honda, M., \& Sadato, N. (2005). Functionally segregated neural substrates for arbitrary audiovisual paired-association learning. Journal of Neuroscience, 25, 6409-6418.

van der Linden, M., Murre, J. J. A., \& van Turennout, M. (2008). Birds of a feather flock together: Experience-driven formation of visual object categories in the human brain. PLOS ONE, 3, e3995.

Weisberg, J., van Turennout, M., \& Martin, A. (2007). A neural system for learning about object function. Cerebral Cortex, 17, 513-521.

$\mathrm{Xu}, \mathrm{Y}$. (2005). Revisiting the role of the fusiform face area in visual expertise. Cerebral Cortex, 15, 1234-1242. 


\section{This article has been cited by:}

1. Lauren E. Marsh, Timothy L. Mullett, Danielle Ropar, Antonia F. de C. Hamilton. 2014. Responses to irrational actions in action observation and mentalising networks of the human brain. NeuroImage . [CrossRef]

2. Yetta Kwailing Wong, Cynthia Peng, Kristyn N. Fratus, Geoffrey F. Woodman, Isabel Gauthier. 2014. Perceptual Expertise and Top-Down Expectation of Musical Notation Engages the Primary Visual Cortex. Journal of Cognitive Neuroscience 26:8, 1629-1643. [Abstract] [Full Text] [PDF] [PDF Plus]

3. Jessica A. Collins, Ingrid R. Olson. 2014. Knowledge is power: How conceptual knowledge transforms visual cognition. Psychonomic Bulletin \& Review 21, 843-860. [CrossRef]

4. Nora Hennies, Penelope A. Lewis, Simon J. Durrant, James Cousins, Matthew A. Lambon Ralph. 2014. Time- but not sleepdependent consolidation promotes the emergence of cross-modal conceptual representations. Neuropsychologia . [CrossRef]

5. C. M. Bird, S. C. Berens, A. J. Horner, A. Franklin. 2014. Categorical encoding of color in the brain. Proceedings of the National Academy of Sciences 111, 4590-4595. [CrossRef]

6. Clara A. Scholl, Xiong Jiang, Jacob G. Martin, Maximilian Riesenhuber. 2014. Time Course of Shape and Category Selectivity Revealed by EEG Rapid Adaptation. Journal of Cognitive Neuroscience 26:2, 408-421. [Abstract] [Full Text] [PDF] [PDF Plus]

7. Marieke van der Linden, Joost Wegman, Guillén Fernández. 2014. Task- and Experience-dependent Cortical Selectivity to Features Informative for Categorization. Journal of Cognitive Neuroscience 26:2, 319-333. [Abstract] [Full Text] [PDF] [PDF Plus]

8. Teresa Wilcox, Amy Hirshkowitz, Laura Hawkins, David A. Boas. 2014. The effect of color priming on infant brain and behavior. NeuroImage 85, 302-313. [CrossRef]

9. J. R. Folstein, T. J. Palmeri, I. Gauthier. 2013. Category Learning Increases Discriminability of Relevant Object Dimensions in Visual Cortex. Cerebral Cortex 23, 814-823. [CrossRef]

10. Antonia Thelen, Céline Cappe, Micah M. Murray. 2012. Electrical neuroimaging of memory discrimination based on single-trial multisensory learning. NeuroImage 62, 1478-1488. [CrossRef]

11. Marieke van der Linden, Miranda van Turennout, Guillén Fernández. 2011. Category Training Induces Cross-modal Object Representations in the Adult Human Brain. Journal of Cognitive Neuroscience 23:6, 1315-1331. [Abstract] [Full Text] [PDF] [PDF Plus] 